\title{
Proposed Model For Teleradiological System For Medical Telediagnosis Process
}

\author{
Rafida Hameed Ahmad \\ Department of Computer Science / College of Education \\ University of Mosul
}

Received

$r \wedge / \cdot \wedge / 200 \wedge$
Accepted

$.7 / 0 \leqslant / 2009$

\section{الخلاصة}

\begin{abstract}
إن لأهمية وحاجة الصورة الثعاعية (Radiograph) في عملية التتخيص الطبي
للمرضى جعلها من أهم مصادر ومعلومات التشخيص في عملية التشخيص الطبي عن بعد.

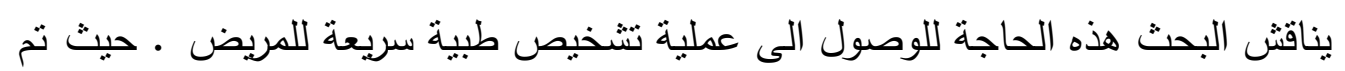

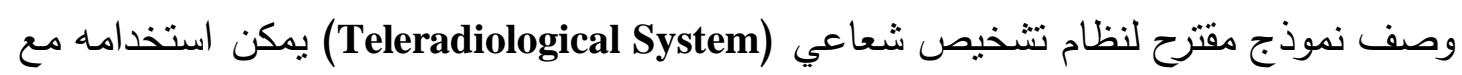
انظمة التشخيص الطبي ة (Telediagnosis System) في المستشفيات المفتوحة على شبكة

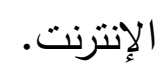

يوضح البحث أيضاً سيناريو هذا النظام ودور الطبيب الأخصائي الثعاعي

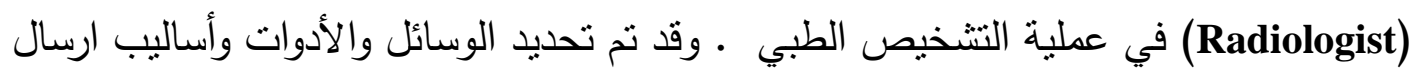

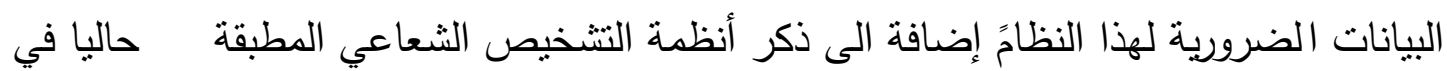

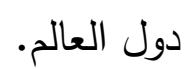

\section{Abstract}

The need and importance of radiographs in the diagnostic process makes the Telediagnosis system depends on the Teleradiology application and its services as important sources for diagnostic information.

This article discusses this need that creates faster diagnosis. A proposed teleradiological prototype system was described, which can be used in the open hospitals on the Internet.

The scenario of such system that explains the role of radiologist in the diagnosis process was explained. The equipments needed for the information of this system, methods of transmission, and some of current teleradiology systems in use were mentioned.

Keywords: Telemedicine, Teleradiology, diagnosis system, medical information. 


\section{Introduction}

Teleradiology plays a large role in the globalization of medicine; it is the transmission of X-ray pictures or various scans such as a CT scan across distances from one location to another in order to create faster diagnosis.

Radiographs are one of the most important sources of diagnostic information [1]. These graphs can be transferred from remote sites for interpreting and diagnosing by the radiologist who resides in a distance place from the patient, this method known as Teleradiology.

Col. Poropatich says: Teleradiology allows doctors to distribute the images to the emergency room, the operating room or the physical therapy area, which makes it a lot easier to provide better patient care [6].

Sixty seven percent of all radiology practices use Teleradiology. This usually benefits patients and radiologists. X-ray patient's examination taken at 3 clock in the morning can be sent out to be read immediately by a radiologist who is at home [7].

In some cases, Teleradiology is not only bringing medicine to the underserved, it is relieving rural hospitals of the burden of attracting their own radiologists.

In a new survey of radiologists across the U.S., an overwhelming majority reports that Teleradiology services have helped them improve patient care and the lives of the physicians who provide it [10].

This article illustrates the services that provided by this application and its communication aspects; a simple prototype for Teleradiology system that used to cooperate between local and regional hospitals in disease diagnosing is explained besides the role of radiologist in the Telediagnosis process. The equipment used for the information of such system and its transmission methods are also discussed.

\section{Services and Communication Aspects:}

There are many services of telemedicine and they are distributed in all its applications, in Teleradiology and through some of the present Teleradiology systems we found several tangible benefits for this applications includes the reduced time and costs of traveling and films, better management of patients, wider delivery of services and intangible benefits such as faster management of medical problems, equitable access to specialist opinion and reduced length of stay [2].

For some applications, synchronous communication is either unnecessary or inadequate. For x-ray and other still-image information specialized workstations have been developed for an acquisition, transfer and remote viewing on computer screens [3]. The work span of the Teleradiological system can be divided into two axes [4].

1 - Remote diagnoses and remote consultation.

2- Electronic transfer and collection of information. 


\section{Telediagnostic Needs:}

Telediagnosis systems are one of the important applications of Telemedicine. In which patient can make diagnosis for his disease remotely by a specific specialist without traveling to his place. The most necessary requirements for such diagnosis are the radiological images that always played an important role in medical diagnosis, and that explain many abnormal points in patient's body.

These can be achieved by the Teleradiological systems that can also be used for remote consultation and interpretation of images and allowing real-time interaction between physicians.

Teleradiology is suitable for providing radiological services to remote medical facilities and $90 \%$ of physicians depend on radiograph images in their diagnosis.

\section{Current Teleradiological Systems:}

There has been tremendous growth of Teleradiology companies both in the United States and abroad. One of the largest is located in India and has a five-story building in India.

Col. Poropatich and Larry Markins, provide telemedicine capabilities in Iraq. They deployed to four sites to set up the equipment: the 31st Combat Support Hospitals (CSH) in Baghdad and Balad and the 67th CSHs in Mosul and Tikrit.

According to Col. Poropatich, one of the largest applications for telemedicine in Iraq is Teleradiology. The primary use of Teleradiology in Iraq is to move CAT scan images from Baghdad or Balad to Landstuhl Regional Medical Center in Germany so the images can be archived.

The field hospital in Bagran, Afghanistan, established a highbandwidth satellite connection with Landstuhl Regional Medical Center in Germany, supporting Combat radiology support in Bagran is equipped for X-ray, ultrasound, and CT [8].

Kalyanpur is the only Indian radiologist providing nighthawk service to the U.S. He receives an average of 25 emergency scans per day from several U.S. hospitals.

The reach of Teleradiology extends to the high seas, although most experts agree that the maritime Teleradiology is still limited. It does allow the transmission of radiographs from a ship anywhere in the world via satellite and Internet links for immediate expert radiological opinion and advice.

\section{Prototype of Teleradiology System:}

Telediagnosis system between the patient and GP/ Physician often depends on its diagnosing on the radiological investigation, so the requester (GP/physician) refers the patient to the nearest radiological unit of the patient to take the investigation. 
After investigation the radiological provider will use the Teleradiology system to make the Interpretation and return back the report to the requester. The scenario of this system includes the roles requester, radiographer and radiologist summarized in figure(2) while the prototype for the Teleradiology system that cooperates with the Telediagnosis system illustrated in figure(1).

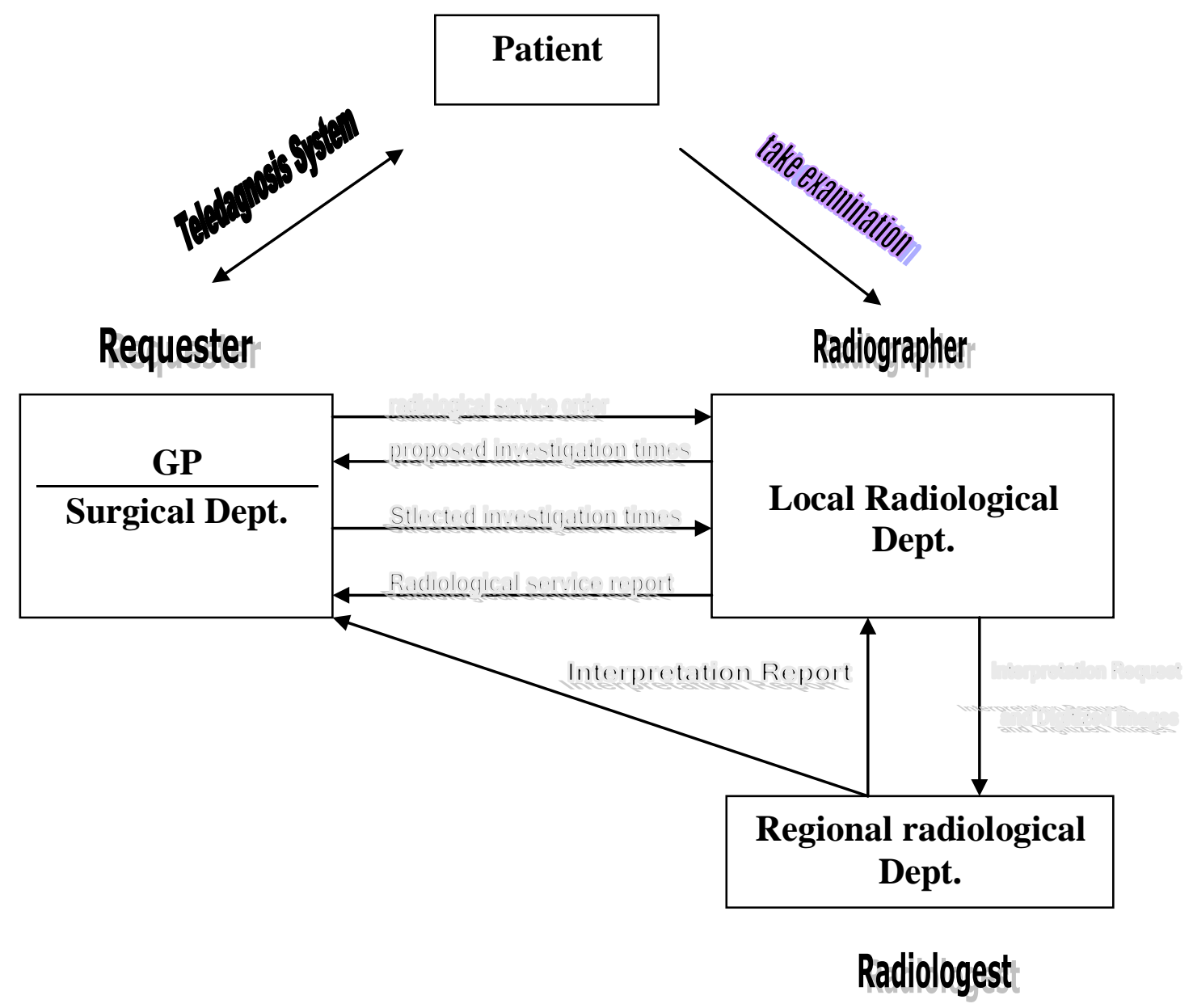

Figure(1): (Prototype of Teleradiological system and its cooperation with Telediagnosis system) 


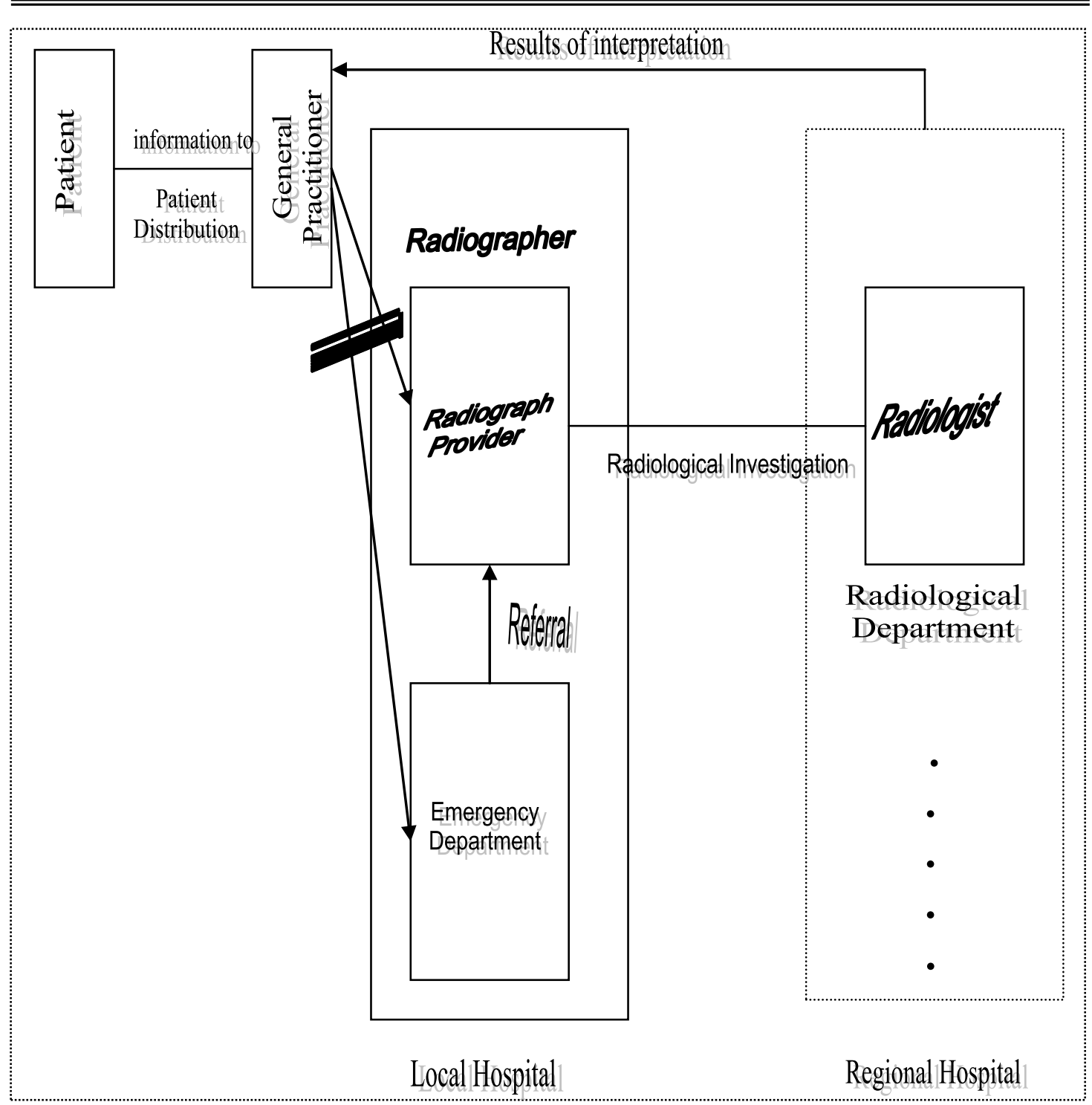

Figure(2): (Scenario of Teleradiological System)

The requester sends a radiological services order to the provider in the local hospital. The provider evaluates the request, and proposes alternative investigation time. After selecting the time by patient who then sees the provider and perform the investigation. After the investigation, the provider (radiographer) will request the radiologist interpretation remotely by transferring the digitized images to the radiologist in the regional hospital for interpretation. Radiological report will be send back to the requester either through the provider or directly. 


\subsection{Teleradiological Equipment}

The hardware and other equipment for Teleradiology systems are dependent on the type of images to be transmitted. Any Teleradiological system must consist of a personal computer (PC), and local hospital that conducted by Teleradiological system must be equipped with a PC and devices for digitizing films and documents (scanner) as well as the investigation equipment for x-ray, CT,MRI and others.

Regional hospital must be equipped with high resolution monitor. Teleradiology workstation, for acquiring, transmitting and display high quality images are next class of equipment.

\section{Transmission of Teleradiology Information:}

Image transmission depends primarily on high-speed electronic communication pipelines such as ATM (Asynchronous Transfer Mode) or gigabit networks that enable rapid transmission of digital images without lossing any content or resolution [9].

Information used in Teleradiology is the images that acquired from radiological modalities that include $\mathrm{x}$-ray, magnetic resonance (MR), computer tomography (CT), ultrasound, nuclear medicine (NM) and others.

$\mathrm{X}$-ray films and digitized with laser scanners, while images from digital imaging modalities such as (MR) and (CT) are available directly in digital [5]. Digitized still images are easily transmitted between PCs; Video signal may be digitized into a series of still images, which can be transmitted between computers.

This information can be transmitted in two modes synchronous (cooperative) or asynchronous. More recently, clinicians have started to use Internet for transmission because of its universal protocol and low cost bandwidth.

So the types of system services and its telecommunication aspects are listed in the following Table-1:

\begin{tabular}{|l|l|}
\hline \multicolumn{1}{|c|}{ Teleradiological Services } & \multicolumn{1}{c|}{ Telecommunication Aspects } \\
\hline -Remote diagnosis ordinary x-ray & - Digitized still pictures/data \\
picture & Communication. \\
-Remote diagnosis computer & - Data communication. \\
Tomography picture. & \\
-Remote diagnosis ultrasonic & - Interactive video/audio. \\
Picture. & \\
-Radiological remote consultation. & - Interactive video/audio \\
& Communication. \\
\hline
\end{tabular}

Table -1: (Teleradiological services and communication aspects) 


\section{Conclusion:}

The most widely deployed application of Telemedicine that must be used in any Telemedicine system is the Teleradiology. Without radiology services, rural hospitals will tell you they cannot keep their doors open. It is a unique combination of digital data network and computer and their function is the electronic transmission of radiographs or radiological images from one site to another. These systems can be implemented as a special network or public network like Internet, the very low cost band-width.

These systems can improve emergency service coverage and integrate multi hospital/ clinics health care provider consortiums. The network of the prototype in this article illustrates the cooperation between local and regional hospitals in radiological services, which help physician in diagnosing and makes it a lot easier to provide better patient care and benefits both patients and radiologists.

\section{References}

1) Sigurd From, Lilly Ann, etal, Telemedicine services integrated into a health care network Journal of Telktronikk 1.93, Norway, (1993).

2) Tin Hayward, John Mitchell, and The cost-effectiveness of Teleradiology at the women's Hospital in Adelaide, Journal of Telemedicine and Telecare. Vol.6, Suppl, P: 23-25, (2000).

3) Vitanen J., Sund T., et al, Nodic Teleradiology development, Computer methods and Programs in Biomedicine, Vol. 37. P:273277, (1992).

4) Birger J. Nymo, Telemedicine, Journal of Telektronikk 1.93, Norway, (1993).

5) James E., Cabral Jr., yongmin K., Multimedia systems for Telemedicine and their Communication requirements. IEEE communication Magazine, July 1996, P: 20, (1996).

6) Cheryl Lilie, Moving Images Not Patients, March 2005.

(http://www.afcea.org/SIGNAL/articles/anmviewer.asp?a=694\&print=yes).

7) Murray Feingold, July, (2007). (http://wbz.com/pages/720271.php?).

8) Douglas page, Teleradiology readies for war, Mar. (2003).

(http://www.dimag.com/pacsweb/printer_friendly/?articleID=47901795)

9) Douglas Page, Demand for medical services in remote areas and staffing shortages push radiology to the ends of the earth, (2003). (http://home.earthlink.net/ douglaspage/id47.html)

10) Teleradiology Survey, November, 1999. (http://www.medicexchange.com/Imported/imported-2042.html) 